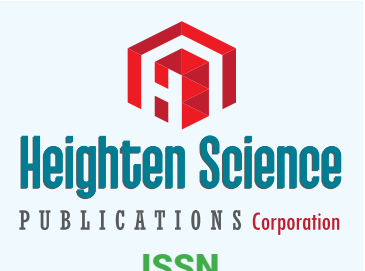

ISSN

2640-2823

\title{
Successful management of disseminated Fusarium infection in a patient with acute myeloid leukemia
}

\author{
AlShammasi S $^{1}$, AlNujaidi D' ${ }^{1}$ Bakhit $K^{3}$, Algarni $A^{2}$ and Al- \\ Anazi KA ${ }^{3 *}$ \\ 'Department of Internal Medicine, King Fahad Specialist Hospital, Dammam, Saudi Arabia \\ ${ }^{2}$ Department of Pathology, King Fahad Specialist Hospital, Dammam, Saudi Arabia \\ ${ }^{3}$ Department of Hematology and Hematopoietic Stem Cell Transplantation, King Fahad \\ Specialist Hospital, Dammam, Saudi Arabia
}

\footnotetext{
*Address for Correspondence: Dr. Khalid Ahmed Al-Anazi, Consultant HematoOncologist and Chairman, Department of Hematology and Hematopoietic Stem Cell Transplantation, Oncology Center, King Fahad Specialist Hospital, P.O. Box: 15215, Dammam 31444, Saudi Arabia, Tel: 966 - 03- 8431111; Fax: 966 -13- 8427420; E-mail:

kaa_alanazi@yahoo.com
}

Submitted: 14 August 2018

Approved: 14 September 2018

Published: 17 September 2018

Copyright: @2018 AIShammasi S, et al. This is an open access article distributed under the Creative Commons Attribution License, which permits unrestricted use, distribution, and reproduction in any medium, provided the original work is properly cited.

Keywords: Acute myeloid leukemia; Disseminated Fusarium infection; Febrile neutropenia; Combined antifungal therapy

Check for updates

\section{Abstract}

Background: Invasive fungal infections cause significant morbidity and mortality in patients with hematologic malignancies and in recipients of hematopoietic stem cell transplantation.

Case: We report a patient with relapsed acute myeloid leukemia who developed disseminated Fusarium infection during the neutropenic period following the salvage cycle of chemotherapy given at King Fahad specialist Hospital in Dammam, Saudi Arabia. The invasive fungal infection was successfully managed with a combination of voriconazole and liposomal amphotericin-B.

Discussion: Fusarium species can cause invasive infections that may become disseminated and life-threatening in patients with acute myeloid leukemia.

Conclusion: Combined antifungal therapy and recovery of neutrophil count are essential to control invasive Fusarium infections.

\section{Introduction}

Invasive fungal infections (IFIs) represent a major complication in patients with acute myeloid leukemia (AML) and in recipients of hematopoietic stem cell transplantation (HSCT) [1-3]. Although invasive aspergillosis is the most frequently reported IFI in AML patients and in recipients of HSCT, infections caused by other molds such as Fusarium species have been increasingly reported [1,2]. Studies have shown that fusariosis is the second major cause of fungal infections in immunocomromised patients [2,4]. However, one study showed that Candida sp. particularly Candida tropicalis is a leading cause of IFIs in certain geographic locations such as Taiwan [3]. Fungal infections have the following portals of entry: skin, respiratory tract through inhalation, mucous membranes and central venous catheters (CVCs) $[1-3,5,6]$.

Invasive or disseminated fusariosis occurs almost exclusively in immunocompromised individuals [2,5]. Disseminated Fusarium infection (DFI) is common in patients with hematologic malignancies (HMs), particularly those with acute leukemia [7]. The risk factors for invasive or disseminated fusariosis in patients with HMs are: (1) the HM itself, (2) neutropenia following induction treatment or subsequent cycles of chemotherapy, and (3) HSCT with its immunosuppression related to conditioning therapy, and prophylaxis as well as treatment of graft versus host disease (GVHD) [1,5,7-9].

\section{Case Presentation}

A 51 year old Saudi lady was diagnosed to have AML at King Fahad Specialist 
Hospital (KFSH) in Dammam in early March 2016. She presented with fever, fatigue and bleeding from mucous membranes. Her physical examination revealed: pallor, clear chest, no external palpable lymphadenopathy, no abdominal tenderness or palpable organomegaly, and normal cardiovascular and neurological examinations. Her complete blood count (CBC) showed: white blood cell count (WBC): $40.05 \times 10^{9} / \mathrm{L}$, hemoglobin (Hb): $9.0 \mathrm{~g} / \mathrm{dL}$, and platelet count (PLT): $19 \times 10^{9} / \mathrm{L}$. Peripheral blood film (PBF) revealed thrombocytopenia and 38\% blast cells. Bone marrow examination (BME) showed cellular marrow with diffuse infiltration with myeloblasts. Cytogenetic analysis showed normal cytogenetics with negative BCR/ABL, FLT3-ITD, MLL, RUNX1 and CBFB. Renal, hepatic, bone and coagulation profiles were all normal. Chest $\mathrm{X}$ ray (CXR), electrocardiogram and echocardiogram did not reveal any abnormality.

After establishing the diagnosis of AML, the patient was commenced on $3+7$ induction cycle of chemotherapy composed of daunorubicin and cytosine arabinoside. Day 14 BME revealed hypocellular marrow without excess of blast cells. Thereafter, there had delayed recovery of blood counts so BMEs were repeated on days 35 and 53 of induction chemotherapy and the findings were similar to those obtained on day 14 . As the patient continued to be clinically frail, requiring prophylactic antimicrobials and frequent blood product transfusions due to persistent pancytopenic and in the absence of donors for allogeneic HSCT, she remained unfit for a new cycle of chemotherapy, but she did not encounter any serious infection.

In July 2016, the patient was seen at the outpatient clinic. She was unwell clinically, but vitally stable. Her CBC showed: WBC of $8.87 \times 10^{9} / \mathrm{L}, \mathrm{Hb}$ of $13.8 \mathrm{~g} / \mathrm{dL}$, and PLTs of: $22 \times 10^{9} / \mathrm{L}$. PBF revealed thrombocytopenia and $36 \%$ circulating myeloblasts. BME was repeated and it showed cellular marrow with diffuse infiltration by myeloblasts. The patient was readmitted for salvage chemotherapy. She received fludarabine, cytosine arabinoside in addition to granulocyte-colony stimulating factor (G-CSF) in order to control her disease.

During the pancytopenic period following the salvage cycle of chemotherapy, the patient developed recurrent episodes of fever which did not respond to the following antimicrobials: piperacillin-tazobactam, amikacin, vancomycin, acyclovir, fluconazole and micafungin. Meanwhile she developed the following complications: (1) multiple indurated skin lesions involving the limbs and trunk that became ulcerated, (2) dyspnea, pleuritic chest pain with clinical evidence of consolidation and pleural effusion, and (3) gradual unilateral reduction in vision followed by loss of vision in one eye. Consequently the patient underwent extensive investigations that revealed: negative serology for viral infections, autoimmune disorders, brucella and syphilis; negative cultures of eye swabs; negative aspergillus gallactomannan test, negative blood cultures and negative BM cultures for tuberculosis, brucellosis and fungal infection. CXR and computerized axial tomography (CAT) scan of the lungs showed bilateral infiltration with airspace consolidation, pulmonary nodules and cavity formation in addition to a right-sided pleural effusion (Figure 1). Skin biopsy showed subcorneal pustular dermatitis as well as fungal hyphae that were branching at acute angles (Figure 2). The fungus was

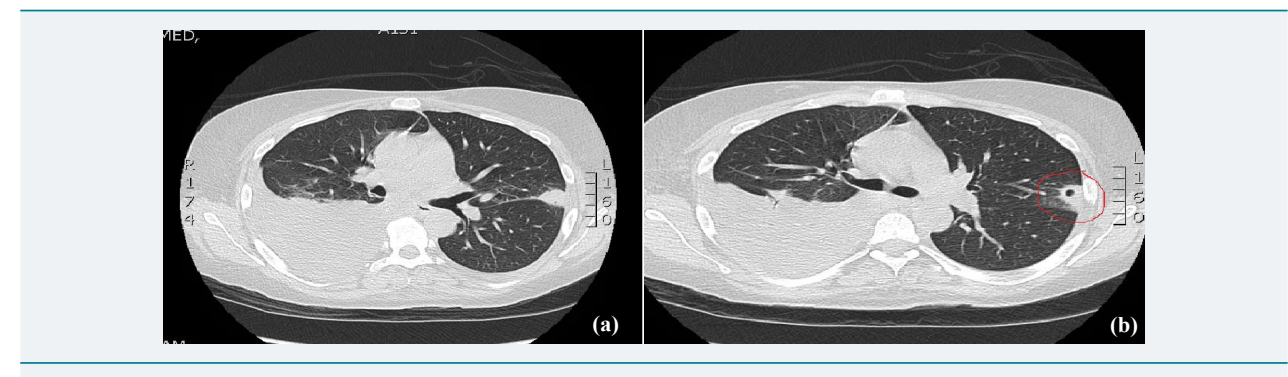

Figure 1: CAT scan of lungs showing: (a) Consolidation, pleural effusions and pulmonary nodules. (b) Consolidation, pleural effusions, pulmonary nodules and cavity formation. 


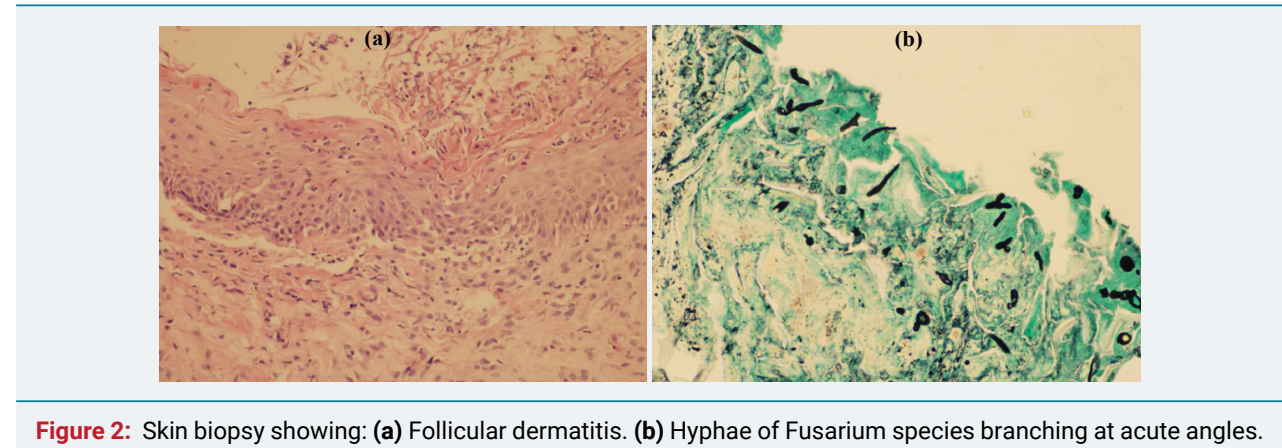

Figure 2: Skin biopsy showing: (a) Follicular dermatitis. (b) Hyphae of Fusarium species branching at acute angles.

identified as Fusarium sp. by electron microscopy and this was confirmed by nested polymerase chain reaction (PCR). CAT scan as well as magnetic resonance imaging (MRI) of the brain revealed no abnormality. MR arteriography of intracranial and extracranial arteries showed no vascular abnormality.

After confirming the presence of disseminated infection caused by Fusarium sp., micafungin was discontinued and the patient was commenced on both liposomal amphotericin-B and voriconazole intravenously (IV) in addition to subcutaneous granulocyte colony stimulating factor (G-CSF). The CVC was removed. Few days later, fever subsided. Later on, the patient started to improve clinically and more improvement was encountered after the recovery of her blood counts. Four weeks after starting combined antifungal therapy, the DFI became under control and the patient regained her vision so she was discharged on oral voriconazole. Six weeks later the patient received a consolidation cycle of chemotherapy composed of intermediate dose cytosine arabinoside (1500 mg/m² IV twice daily for 3 days) in order to keep her AML under control. She received voriconazole prophylaxis so as not to reactivate her previous Fusarium infection. Later on, the patient was followed up regularly in the outpatient clinic.

\section{Discussion}

Fusarium is a rapidly emerging multidrug resistant (MDR) genus of fungal opportunists that was first identified in the year 1958 [10]. Fusarium sp. are widely distributed in soil, plant debris, water and other organic substances [11,12]. Areas of high incidence of DFIs include: the United States of America, France, Germany, Italy, Netherland, Mexico, Australia and India [10,13]. For many years, Fusarium sp. have been considered as important plant pathogens $[11,12]$. Recently, more than 100 Fusarium sp. have been identified, but only 12 species are associated with human infections. The most frequent Fusarium sp. that cause human infections are: F. solani, F. oxysporum, F. verticillioidis, and F. moniliforme, while the less frequent F. species that cause infections in humans include: F. proliferatum, F dimerum, F. chlamidosporum, F. sacchari, and F. antophilum [11-14].

In humans, Fusarium sp. can cause a wide range of infections ranging from local and superficial infections to disseminated, invasive and bloodstream infections [11,12,14-17]. Examples of the specific infections that can be caused by Fusarium sp. include: keratitis, endophthalmitis, onychomycosis, cutaneous and subcutaneous nodules, osteomyelitis, septic arthritis, sinusitis, CVC-related infections, meningitis, brain abscess, peritonitis, pneumonia, disseminated and bloodstream infections [11,12,14-17].

The risk factors for invasive or DFIs include: HMs particularly AML, acute lymphoblastic leukemia (ALL), lymphoma, and multiple myeloma; recipients of HSCT particularly those having GVHD; recipients of solid organ transplantations; solid tumors; human immunodeficiency virus patients; drugs such as corticosteroids, immunosuppressive agents and cytotoxic chemotherapy; neutropenia; hyperglycemia; burns; wounds; CVCs; active smoking; blood transfusions; pyoderma gangrenosum; and previous IFI [1,2,57,11,13,14,16,17,18-37]. In patients with HMs who are severely immunocompromised, 
airborne transmission of invasive fusariosis may occur [38]. The sites of invasive infections caused by Fusarium sp. include: skin, lung, sinuses, disseminated and bloodstream infections $[10,36]$.

The following techniques have been employed in the diagnosis of infections caused by Fusarium sp.: (1) microscopic identification and culture methods such as: blood cultures, tissue cultures and cultures of tissue biopsies taken from skin, sinuses, lungs and other internal organs; (2) serological assays such as galactomannan and $\beta$-glucagon tests; (3) specific nested PCR for identification and antimicrobial susceptibility testing; and (4) mass spectroscopy techniques [11,12,14,35]. Therapeutic options that are available for the treatment of infections caused by Fusarium sp. include: (1) single antifungal agents including: amphotericin-B, voriconazole, posaconazole and itraconazole; (2) combination therapies including either two antifungal agents such as voriconazole + amphotericin- $B$, voriconazole + terbinafine, caspofungin + amphotericn- $B$ or amphotericin- $\mathrm{B}+$ terbinafine; or one antifungal drug + one non-antimycotic agent such as: voriconazole + metronidazole, and liposomal amphotericin-B + ciprofloxacin or ibuprofen; (3) adjunctive therapies such as: surgical debridement of infected tissues, debulking surgery such as splenectomy, removal of infected or colonized CVCs, interferon- $\gamma$, G-CSF, and granulocyte transfusions; and (4) new agents such as: MGCD290 and isavaconazole $[2,4,6-11,14,18-20,34-36]$. In severely immunocompromised patients who are at high-risk of having DFIs, antifungal prophylaxis is indicated $[14,15]$.

The prognosis of fusariosis is directly related to the immune status of the affected patient and to the extent of the infection. Hence, very high mortality rates are encountered in persistently immunocompromised individuals [11,14]. Persistent neutropenia and a recent glucocorticoid therapy are the only independent factors for poor outcome [14]. In DFI, the overall mortality rate is $50 \%$ to $80 \%[14,15,36]$. However, in patients with disseminated infection and persistent neutropenia, mortality rate may reach $100 \%$ [11].

Our patient had the following risk factors for the development of DFI: (1) AML in relapse, (2) repeated cycles of cytotoxic chemotherapy, (3) presence of a CVC at the time of infection, and (4) prolonged periods of neutropenia following the 2 cycles of chemotherapy. Unfortunately, there was no response to several antimicrobials given to control febrile neutropenia (FN) encountered after salvage chemotherapy. After confirming the presence of DFI, the patient was commenced on IV voriconazole in combination with liposomal amphotericin-B and G-CSF. Few days later, the patient started to show response and after recovery of her neutrophil count she experienced accelerated recovery and her disseminated infection was ultimately controlled. The combined antifungal therapy and the recovery of her WBC count were critical to control her life-threatening infection.

In conclusion: neutropenic patients with AML are at risk of serious fungal infections. In situations where a patient with acute leukemia develops FN that does not show favorable response to broad spectrum antimicrobials, it is essential to have comprehensive investigations in order to determine the cause of FN then to tailor antimicrobial therapy accordingly.

\section{Acknowledgement}

We are grateful to all medical, nursing and technical staff at KFSH in Dammam, Saudi Arabia who took care of the patient presented.

\section{References}

1. Garnica $M$, da Cunha MO, Portugal $R$, Maiolino $A$, Colombo $A L$, et al. Risk factors for invasive fusariosis in patients with acute myeloid leukemia and in hematopoietic cell transplant recipients. Clin Infect Dis. 2015; 60: 875-880. Ref.: https://goo.gl/4ZgKKE 
2. De Pinho DB, Fernandes LL, Carvalho Barreiros Mda G, Quintella LP, Sodré CT, et al. Disseminated fusariosis in a bone marrow transplant patient. J Clin Aesthet Dermatol. 2012; 5: 40-42. Ref.: https://goo.gl/jVtmkK

3. Tang JL, Kung HC, Lei WC, Yao M, Wu Ul, et al. High incidences of ilnvasive fungal infections in acute myeloid leukemia patients receiving induction chemotherapy without systemic antifungal prophylaxis: a prospective observational study in Taiwan. PLoS One. 2015; 10: e0128410. Ref.: https://goo.gl/j2aXk7

4. Bose P, Parekh HD, Holter JL, Greenfield RA. Disseminated fusariosis occurring in two patients despite posaconazole prophylaxis. J Clin Microbiol. 2011; 49: 1674-1675. Ref.: https://goo.gl/7qMhk9

5. Uludokumacı S, Balkan II, Mete B, Ozaras R, Saltoğlu N, et al. Ecthyma gangrenosum-like lesions in a febrile neutropenic patient with simultaneous pseudomonas sepsis and disseminated fusariosis. Turk J Haematol. 2013; 30: 321-324. Ref.: https://goo.gl/xYs5Bu

6. Sheela S, Ito S, Strich JR, Manion M, Montemayor-Garcia C, et al. Successful salvage chemotherapy and allogeneic transplantation of an acute myeloid leukemia patient with disseminated Fusarium solani infection. Leuk Res Rep. 2017; 8: 4-6. Ref.: https://goo.gl/hhHgyc

7. Dony A, Perpoint $T$, Ducastelle $S$, Ferry $T$. Disseminated fusariosis with immune reconstitution syndrome and cracking mycotic aortic aneurysm in a 55-year-old patient with acute myeloid leukaemia. BMJ Case Rep. 2013; 2013. bcr2013201050. Ref.: https://goo.gl/jziSxt

8. Bourgeois GP, Cafardi JA, Sellheyer K, Andea AA. Disseminated Fusarium infection originating from paronychia in a neutropenic patient: a case report and review of the literature. Cutis. 2010; 85: 191194. Ref.: https://goo.gl/TC7qpY

9. Efe İris N, Güvenç S, Özçelik T, Demirel A, Koçulu S, et al. Successful treatment of disseminated fusariosis with the combination of voriconazole and liposomal amphotericin B. Turk J Haematol. 2016; 33: 363-364. Ref.: https://goo.gl/ERqDN9

10. Al-Hatmi AM, Hagen F, Menken SB, Meis JF, de Hoog GS. Global molecular epidemiology and genetic diversity of Fusarium, a significant emerging group of human opportunists from 1958 to 2015. Emerg Microbes Infect. 2016; 5: e124. Ref.: https://goo.gl/MrL1ug

11. Nucci $M$, Anaissie E. Fusarium infections in immunocompromised patients. Clin Microbiol Rev. 2007; 20: 695-704. Ref.: https://goo.gl/YZKZd4

12. Nelson PE, Dignani MC, Anaissie EJ. Taxonomy, biology, and clinical aspects of Fusarium species. Clin Microbiol Rev. 1994; 7: 479-504. Ref.: https://goo.gl/LjQrLG

13. Binder U, Lass-Flörl C. Epidemiology of invasive fungal infections in the mediterranean area. Mediterr J Hematol Infect Dis. 2011; 3: e20110016. Ref.: https://goo.gl/fuBgaQ

14. Nucci M, Anaisssie E. Treatment and prevention of Fusarium infection. Edited by: Kauffman CA. Up To Date 2018. Ref.: https://goo.gl/hAUHtg

15. Varon AG, Nouér SA, Barreiros G, Trope BM, Akiti T, et al. Antimold prophylaxis may reduce the risk of Invasive fusariosis in hematologic patients with superficial skin lesions with positive culture for Fusarium. Antimicrob Agents Chemother. 2016; 60: 7290-7294. Ref.: https://goo.gl/oEYuV3

16. Summerbell RC, Richardson SE, Kane J. Fusarium proliferatum as an agent of disseminated infection in an immunosuppressed patient. J Clin Microbiol. 1988; 26: 82-87. Ref.: https://goo.gl/Sk5UXw

17. Kiehn TE, Nelson PE, Bernard EM, Edwards FF, Koziner B, et al. Catheter-associated fungemia caused by Fusarium chlamydosporum in a patient with lymphocytic lymphoma. J Clin Microbiol. 1985; 21: 501-504. Ref.: https://goo.gl/vRy51H

18. Perini GF, Camargo LF, Lottenberg CL, Hamerschlak N. Disseminated fusariosis with endophthalmitis in a patient with hematologic malignancy. Einstein (Sao Paulo). 2013; 11: 545-546. Ref.: https://goo.gl/1YiyTH

19. Latif AL, Harper, Macdonald I, Morrison A. Splenectomy as an effective debulking therapy for disseminated mould infection in acute myeloid leukaemia following adjuvant therapy with interferon gamma and liposomal amphotericin. Med Mycol Case Rep. 2012; 1: 82-84. Ref.: https://goo.gl/72y4My

20. Lockwood MB, Crescencio JC. Adventitious sporulation in Fusarium: The yeast that were not. IDCases. 2015; 3: 5-7. Ref.: https://goo.gl/CLfytq

21. Kah TA, Yong KC, Rahman RA. Disseminated fusariosis and endogenous fungal endophthalmitis in acute lymphoblastic leukemia following platelet transfusion possibly due to transfusion-related immunomodulation. BMC Ophthalmol. 2011; 11: 30. Ref.: https://goo.gl/GXt4Bp

22. Tezcan G, Ozhak-Baysan B, Alastruey-Izquierdo A, Ogunc D, Ongut G, et al. Disseminated fusariosis caused 
by Fusarium verticillioides in an acute lymphoblastic leukemia patient after allogeneic hematopoietic stem cell transplantation. J Clin Microbiol. 2009; 47: 278-281. Ref.: https://goo.gl/sUTxBu

23. Durand-Joly I, Alfandari S, Benchikh Z, Rodrigue M, Espinel-Ingroff A, et al. Successful outcome of disseminated Fusarium infection with skin localization treated with voriconazole and amphotericin B-lipid complex in a patient with acute leukemia. J Clin Microbiol. 2003; 41: 4898-900. Ref.: https://goo.gl/HQPVLS

24. Liu YS, Wang NC, Ye RH, Kao WY. Disseminated Fusarium infection in a patient with acute lymphoblastic leukemia: A case report and review of the literature. Oncol Lett. 2014; 7: 334-336. Ref.: https://goo.gl/smCTuQ

25. Austen B, McCarthy H, Wilkins B, Smith A, Duncombe A. Fatal disseminated fusarium infection in acute lymphoblastic leukaemia in complete remission. J Clin Pathol. 2001; 54: 488-490. Ref.: https://goo.gl/Eu8sBD

26. Vagace JM, Sanz-Rodriguez C, Casado MS, Alonso N, Garcia-Dominguez M, et al. Resolution of disseminated fusariosis in a child with acute leukemia treated with combined antifungal therapy: a case report. BMC Infect Dis. 2007; 7: 40. Ref.: https://goo.gl/mVDrry

27. Young NA, Kwon-Chung KJ, Kubota TT, Jennings AE, Fisher RI. Disseminated infection by Fusarium moniliforme during treatment for malignant lymphoma. J Clin Microbiol. 1978; 7: 589-594. Ref.: https://goo.gl/JzNFSX

28. de Souza M, Matsuzawa T, Lyra L, Busso-Lopes AF, Gonoi T, et al. Fusarium napiforme systemic infection: case report with molecular characterization and antifungal susceptibility tests. Springerplus. 2014; 3: 492. Ref.: https://goo.gl/eYVkHH

29. Esnakula AK, Summers I, Naab TJ. Fatal disseminated fusarium infection in a human immunodeficiency virus positive patient. Case Rep Infect Dis. 2013; 2013: 379320. Ref.: https://goo.gl/9cncX3

30. Lortholary O, Obenga G, Biswas P, Caillot D, Chachaty E, et al. International retrospective analysis of 73 cases of invasive fusariosis treated with voriconazole. Antimicrob Agents Chemother. 2010; 54: 4446-4450. Ref.: https://goo.gl/DvvsrA

31. Muhammed M, Anagnostou T, Desalermos A, Kourkoumpetis TK, Carneiro HA, et al. Fusarium infection: report of 26 cases and review of 97 cases from the literature. Medicine (Baltimore). 2013; 92: 305-316. Ref.: https://goo.gl/Q9HyL7

32. Carneiro HA, Coleman JJ, Restrepo A, Mylonakis E. Fusarium infection in lung transplant patients: report of 6 cases and review of the literature. Medicine (Baltimore). 2011; 90: 69-80. Ref.: https://goo.gl/adyUag

33. Carlesse F, Amaral AC, Gonçalves SS, Xafranski H, Lee MM, et al. Outbreak of Fusarium oxysporum infections in children with cancer: an experience with 7 episodes of catheter-related fungemia. Antimicrob Resist Infect Control. 2017; 6: 93. Ref.: https://goo.gl/qrnM82

34. Nucci M, Varon AG, Garnica M, Akiti T, Barreiros G, et al. Increased incidence of invasive fusariosis with cutaneous portal of entry, Brazil. Emerg Infect Dis. 2013; 19: 1567-1572. Ref.: https://goo.gl/UHKwjS

35. Muhammed M, Coleman JJ, Carneiro HA, Mylonakis E. The challenge of managing fusariosis. Virulence. 2011; 2: 91-96. Ref.: https://goo.gl/UzK1tA

36. Mousset S, Buchheidt D, Heinz W, Ruhnke M, Cornely OA, et al. Treatment of invasive fungal infections in cancer patients-updated recommendations of the Infectious Diseases Working Party (AGIHO) of the German Society of Hematology and Oncology (DGHO). Ann Hematol. 2014; 93: 13-32. Ref.: https://goo.gl/zgdS29

37. Amirrajab N, Aliyali M, Mayahi S, Najafi N, Abdi R, et al. Co-infection of invasive pulmonary aspergillosis and cutaneous Fusarium infection in a patient with pyoderma gangrenosum. J Res Med Sci. 2015; 20: 199-203. Ref.: https://goo.gl/Qom7sL

38. Moretti ML, Busso-Lopes AF, Tararam CA, Moraes R, Muraosa $\mathrm{Y}$, et al. Airborne transmission of invasive fusariosis in patients with hematologic malignancies. PLoS One. 2018; 13: e0196426. Ref.: https://goo.gl/769WMa 